\title{
Safety and efficacy of anaplastic lymphoma kinase tyrosine kinase inhibitors in non-small cell lung cancer (Review)
}

\author{
LI WANG ${ }^{1,2}$ and WEN WANG ${ }^{1,2}$ \\ ${ }^{1}$ Shanghai R\&D Center, Jiangsu Simcere Pharmaceutical Co., Ltd., Shanghai 201318; \\ ${ }^{2}$ The State Key Laboratory of Translational Medicine and Innovative Drug Development, \\ Affiliated with Jiangsu Simcere Pharmaceutical Co., Ltd., Nanjing, Jiangsu 210042, P.R. China
}

Received February 26, 2020; Accepted July 31, 2020

DOI: $10.3892 /$ or.2020.7851

\begin{abstract}
Since the discovery of targeted therapy with epidermal growth factor receptor (EGFR), anaplastic lymphoma kinase (ALK) tyrosine kinase inhibitors (TKIs) have been introduced as the first-line treatment for non-small cell lung cancer (NSCLC) patients who carry sensitizing ALK-activating mutations. Compared with conventional chemotherapeutic regimens, small-molecule ALK-TKIs exhibit excellent clinical efficacy in ALK-positive NSCLC. A series of studies have indicated that ALK-TKI agents as the first-line treatment, including crizotinib, ceritinib, brigatinib, alectinib and entrectinib, can benefit patients with ALK-positive NSCLC. However, resistance to ALK-TKIs has emerged. ALK-TKIs are associated with significantly disabling and undesirable effects that adversely impact quality of life and compliance. This study reviews the pharmacodynamics, efficacy and safety of ALK-TKI agents in order to summarize these effects as well as the relevant management strategies. It is worth emphasizing that the frequency and severity of an adverse effect often varies across different trials.
\end{abstract}

\section{Contents}

1. Introduction

2. Approved ALK-TKIs

3. Safety evaluation

4. Future directions

Correspondence to: Dr Wen Wang, Shanghai R\&D Center, Jiangsu Simcere Pharmaceutical Co., Ltd., 118, Furonghua Road, Pudong, Shanghai 201318, P.R. China

E-mail: wangwen@simcere.com; ortho123@hotmail.com

Key words: anaplastic lymphoma kinase tyrosine kinase inhibitors, crizotinib, ceritinib, brigatinib, alectinib, lorlatinib, entrectinib, safety, non-small cell, efficacy

\section{Introduction}

NSCLC is considered as one of the main causes of cancer-related deaths worldwide, accounting for approximately $80-85 \%$ of all histological subtypes of lung cancer $(1,2)$. Patients with NSCLC are often diagnosed at advanced stages of the disease $(3,4)$. The administration of conventional chemotherapeutic regimens only marginally improves the outcomes of these individuals. The median survival time of these individuals is less than one year after diagnosis and is driven by the molecular expression and genetic mutations of the tumor $(3,4)$. The identification of patients harboring activated EGFR mutations and ALK rearrangements, which account for approximately 15 and $5 \%$ of advanced non-squamous lung carcinomas in Western countries (5), respectively, has led to the targeting of genomic alterations for the treatment of these patients. The development of EGFR-TKIs has fueled efforts to identify additional targeted therapies for NSCLC (6).

ALK, a transmembrane tyrosine kinase, belongs to the superfamily of insulin receptors that regulate cellular growth and may trigger neoplastic transformation, including platelet-derived growth factor receptors, the epidermal growth factor receptor, human epidermal growth factor receptor type 2 , and insulin-like growth factor-1 receptors. ALK catalyzes the phosphorylation reaction of a tyrosine residue on a substrate protein $(7,8)$. In fact, the activation mechanism of ALK is still not completely understood. Phosphorylation of these ALK residues can transmit ALK-mediated signals to downstream signaling pathways (7).

With the development of targeted therapy, the discovery that ALK mutations and rearrangements in NSCLC patients lead to abnormal signaling pathways has markedly changed the targeted therapy in this subset of patients (6). Aberrantly formed ALK oncogenes, mainly caused by fusion mutations, ALK gain-of-function mutations, or ALK amplification, have been identified in various cancers, such as NSCLC, anaplastic large-cell lymphoma (ALCL), inflammatory myofibroblastic tumors (IMTs), and neuroblastoma (9). In patients with NSCLC, the gene rearrangement of echinoderm microtubule-associated protein-like 4 (EML4) ALK is the most common ALK alteration, accounting for 4 to $7 \%$ of lung adenocarcinomas $(9,10)$. Compared with conventional chemotherapeutic regimens, small-molecule ALK-TKIs exhibit excellent clinical efficacy 
in ALK-positive NSCLC (11). In recent years, several ALK inhibitors have been developed to target dysregulated kinases. Crizotinib, which was launched in 2011, is a first-generation ALK inhibitor $(12,13)$. The second-generation inhibitors include ceritinib, alectinib, brigatinib and entrectinib (Fig. 1). Lorlatinib (Table I) is a third-generation inhibitor (13-16). In addition, ensartinib, repotrectinib, and belizatinib are being investigated in ongoing clinical studies (17). It has been revealed that the median progression-free survival in patients using crizotinib was longer than that in patients undergoing chemotherapy in advanced ALK-positive lung cancer patients (12). However, resistance to the first-generation agent crizotinib has emerged in some clinical trials $(18,19)$. Due to the poor blood-brain barrier penetration of crizotinib, brain metastases can present during the first year or two years of treatment (20).

This resistance of ALK is underpinned by different genetic mechanisms that include i) the development of secondary resistance mutations in ALK, such as L1196M $(21,22)$, which most likely corresponds to a gatekeeper residue or a residue located in the ATP-binding pocket of a protein kinase that, when mutated, causes a change in the structure of the kinase that prevents TKI binding; ii) ALK copy number alterations; iii) aberrant activation of alternate kinases leading to ALK-independent growth, such as EGFR; and iv) epithelial-mesenchymal transition (23). L1196M (7\%), G1269A (4\%), C1156Y (2\%), G1202R (2\%), I1171T (2\%), S1206Y (2\%), and E1210K (2\%) are the most common ALK-resistant mutations associated with crizotinib $(21,22)$. The next-generation ALK inhibitors are generally active in crizotinib-resistant mutations, and novel mutations resistant to each of these agents have rapidly become apparent (22). Brigatinib was also found to inhibit nine different mutants with 3-54-fold greater potency than ceritinib and/or alectinib (24).

This review summarizes the pharmacology and clinical safety/efficacy associated with ALK-TKIs. The review is based principally on drug evaluation reports and the latest prescribing information provided by the United States Food and Drug Administration (FDA) supplemented as appropriate by published literature on agents under investigation. It is worth emphasizing that the frequency and severity of an adverse effect often varies across different trials, especially when there are different patient populations or indications under investigation, different treatment regimens and different sample sizes.

\section{Approved ALK-TKIs}

Thus far, six ALK-TKIs have been approved by the FDA and the European Medicines Agency (EMA). They are listed in Table I. The currently approved agents are different in terms of their selectivity and reversibility due to the presence of compound structures, which have been listed in Fig. 1. Table II revealed that the physicochemical properties of agents may be associated with compound structures.

First-generation ALK-TKI, crizotinib. Crizotinib is considered as a first-generation inhibitor of ALK indicated for the treatment of patients with metastatic NSCLC whose tumors are ALK-positive or c-ros oncogene 1 (ROS1)-positive (25).
Crizotinib was approved by the US FDA in 2011. The recommended dosage of crizotinib is $250 \mathrm{mg}$ orally twice daily with or without food (26). A pharmacokinetics study demonstrated that there was no statistically significant difference between fasted and fed in patients with crizotinib, while the exposure of crizotinib with a high-fat meal was slightly reduced compared with the exposure without a meal (27). Additional PK analyses (Table III) revealed that the bioavailability was $43 \%$. Furthermore, ethnicity and age have been found to influence crizotinib PK (28). A clinical trial demonstrated that the mean $\mathrm{C}_{\max }$ and $\mathrm{AUC}$ in Asian patients were 1.50 and 1.57, respectively, compared with those in non-Asian patients (29). A phase I dose-escalation study in adolescents revealed that the recommended dose exceeded the dosage in adults. Hepatic impairment and renal impairment affect the exposure of crizotinib in plasma $(30,31)$. Therefore, crizotinib should be administered to these types of patients with an appropriate dose adjustment.

The concentration of crizotinib in plasma may be affected by its interaction with other drugs. Because crizotinib is metabolized by hepatic cytochrome enzyme P450, particularly CYP3A4 (28), the drug may be affected by inhibitors and inducers of CYP3A4, which are listed in able Table IV. Ketoconazole can increase the $\mathrm{AUC}_{\text {inf }}$ of crizotinib by 3.2-fold, and rifampin can decrease crizotinib exposure (32). Patients should thus be made aware of this fact when concomitantly using crizotinib and inhibitors and inducers of CYP.

Crizotinib has demonstrated safety and antitumor activity in patients with ALK-positive advanced NSCLC in a series of clinical trials. The PROFILE series showed consistent safety and efficacy superior to chemotherapy (33). The phase III (PROFILE 1007, PROFILE 1014), randomized, open-label study $(34,35)$ was a milestone for ALK-TKIs, revealing superior progression-free survival (PFS) and objective response rates (ORRs) comparing crizotinib with standard chemotherapy. In the PROFILE 1007 study, which is the second-line setting, the median progression-free survival (PFS) of crizotinib compared with chemotherapy was 7.7 months vs. 3.0 months [hazard ratio (HR) 0.49 ; $95 \%$ confidence intervals (CIs), 0.37 to 0.64 ], and the response rate was higher with crizotinib than with chemotherapy [65\% (95\% CI, 58 to 72) vs. $20 \%$ (95\% CI, 14 to 26)]. However, there was a statistically significant difference in the median overall survival between the two arms, which is listed in Table V. In the firstline setting (PROFILE 1014), the median PFS of crizotinib vs. chemotherapy was 10.9 vs. 7.0 (HR, 0.45; $95 \%$ CIs, 0.35 to 0.60 ). The objective response rates (ORR) was $74 \%$ vs. $45 \%$. In another study (data from PROFILE 1007 and PROFILE 1014) (36), a randomized trial in Asian patients demonstrated the same result, revealing that the PFS was longer in the crizotinib group than in the chemotherapy group, with a median PFS of 8.1 and 2.8 months, respectively. However, due to ALK mutations and poor blood-brain barrier penetration, patients still experienced relapse and brain metastases within 11 months of treatment $(37,38)$.

\section{Second-generation ALK-TKIs}

Ceritinib. Ceritinib is a tyrosine kinase inhibitor against multiple targets, including ALK, the insulin-like growth factor 1 receptor (IGF-1R), the insulin receptor (InsR), and ROS1 (39). As a selective oral ALK inhibitor, ceritinib has a 20 times 


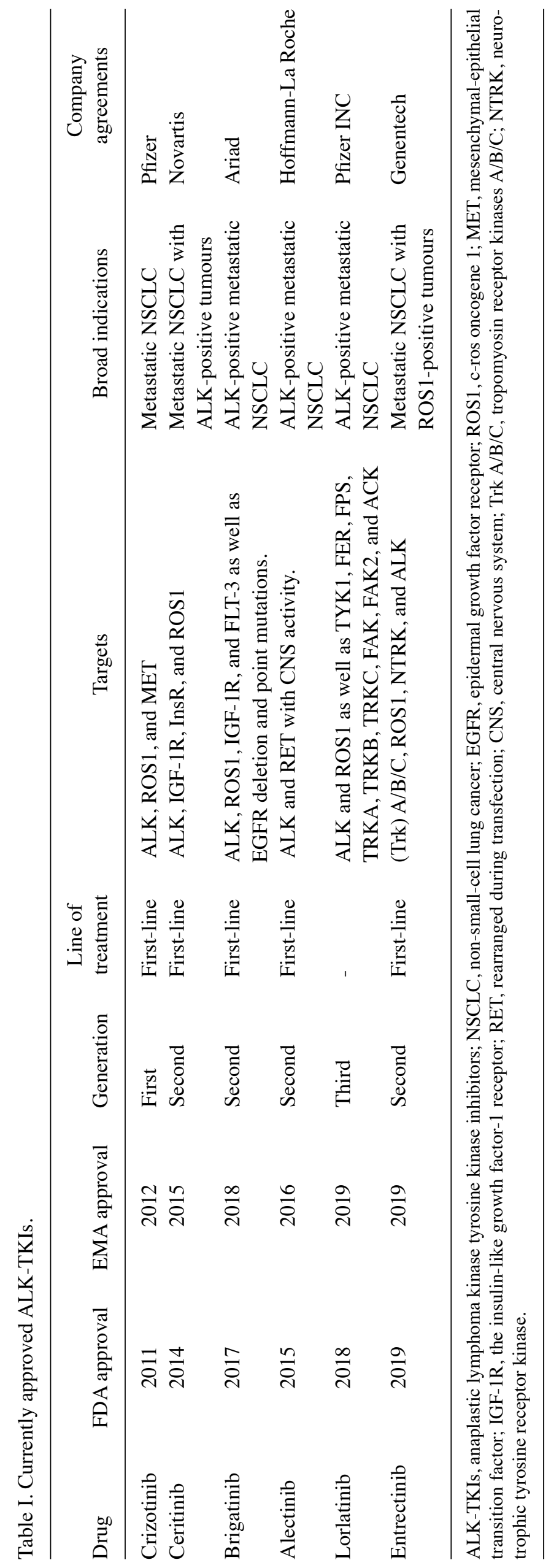


A

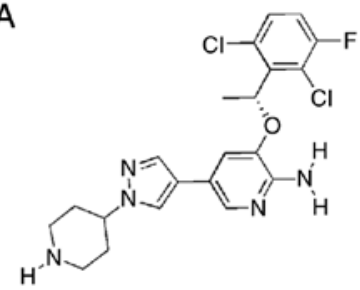

D

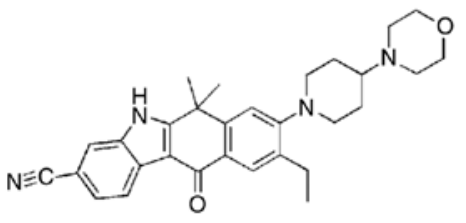

B

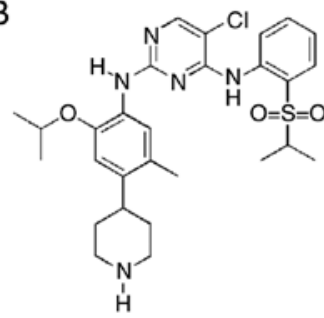

$\mathrm{E}$

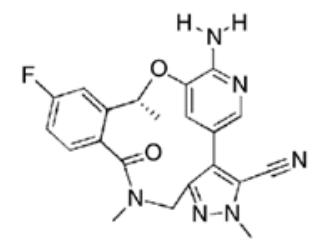

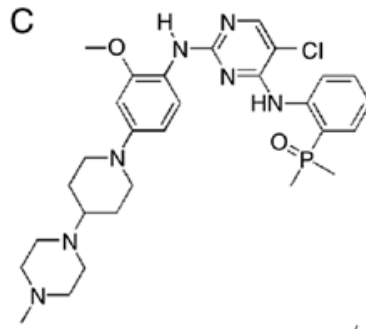

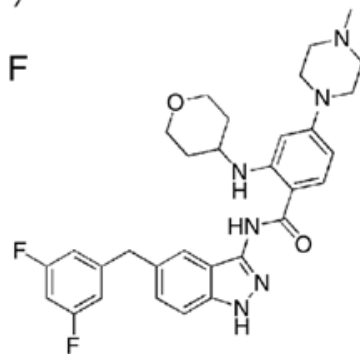

Figure 1. Structural formula of approved ALK-TKIs. (A) Crizotinib, (B) ceritinib, (C) brigatinib, (D) alectinib, (E) lorlatinib and (F) entrectinib. ALK-TKIs, anaplastic lymphoma kinase tyrosine kinase inhibitors.

greater potency than crizotinib against ALK-rearranged lung cancer cell lines in enzymatic assays (40). In addition, it can cross the blood-brain barrier (41). Ceritinib received approval from the FDA as a first-line treatment in patients with NSCLC, and in 2017, it was indicated for metastatic ALK-positive NSCLC. Ceritinib should be taken at a dosage of $450 \mathrm{mg}$ once daily with food (42). The PK profile of ceritinib is listed in Table III and reveals that the drug is similar to crizotinib. Furthermore, ceritinib is mainly metabolized by P450 in the liver (37). Consequently, CYP3A inhibitors may increase the exposure of ceritinib in plasma. Warfarin, midazolam, and rifampin, which are strong CYP3A inhibitors, augment ceritinib in plasma (32).

Due to the poor blood-brain barrier penetration of crizotinib, a large number of patients develop CNS metastases and experience relapse within one year (37). Ceritinib has good blood-brain barrier penetration and can overcome some resistance caused by crizotinib (13). Ceritinib is sensitive to L1196M, G1269A, C1156Y, I1171T, and S1206Y (22). The ASCEND series revealed consistent and durable antitumor activity and tolerable safety in the ASCEND-1 and ASCEND-2 studies $(11,37)$. Ceritinib provided a first-line treatment due to potent activity in crizotinib-naïve patients and significant improvements in PFS (16.6 vs. 8.1 months) compared with the chemotherapy group in the ASCEND-4 study (43). In the ASCEND-5 study (44), 231 patients with ALK-positive NSCLC were randomized. The results revealed that the median PFS resulting from ceritinib was longer than that resulting from chemotherapy [5.4 months (95\% CI, 4.1-6.9) in the ceritinib arm vs. 1.6 months $(95 \% \mathrm{CI}, 1.4-2.8)$ in the chemotherapy arm (HR, 0.0.49; 95\% CI, 0.36-0.67; Table V)].

Alectinib. Alectinib is a selective tyrosine kinase inhibitor that targets ALK and receptor of tyrosine kinase (RET); it has CNS activity and has been approved for advanced ALK-positive NSCLC patients with/without previous treatment with crizotinib (20). Alectinib has a five-fold higher potency than crizotinib for inhibiting ALK and maintains activity against several of the secondary mutants associated with resistance to crizotinib (45).
Due to its clinical efficacy, good blood-brain barrier penetration, and tolerance, alectinib was approved in 2015 by the FDA as a front-line therapy for parents with advanced ALK-positive NSCLC $(18,20)$. The recommended dose is $600 \mathrm{mg}$ orally twice daily, and it should also be taken with food. A clinical trial demonstrated that a high-fat meal could increase the concentration of alectinib in plasma (46). Due to the similar structure between alectinib and ceritinib, the PK profiles of both are similar. The metabolism of alectinib occurs mainly through CYP3A4 in the liver, indicating that CYP3A4 inhibitors and inducers affect the PK of alectinib administration. The plasma protein binding rate was $99 \%$. However, for patients with mild or moderate renal or hepatic impairment, there is no need to adjust the dose (20).

Alectinib is another ALK-TKI that can overcome the poor CNS penetration of crizotinib and crizotinib resistance, and it is sensitive to C1156, G1269A, S1206Y, and L1152R (19). The ALUR trial (47) revealed that the systemic and CNS efficacy in the alectinib arm was significantly improved compared with that in the chemotherapy arm for crizotinib-pretreated ALK-positive NSCLC patients; the median investigator-assessed PFS was 9.6 months vs. 1.4 months. Furthermore, the PFS assessed by the Independent Review Committee was 7.1 months for alectinib and 1.6 months for chemotherapy (HR, 0.32; 95\% CI, 0.17-0.59, P<0.001). In a subgroup of patients with measurable baseline central nervous system (CNS) disease, the CNS ORR was significantly higher with alectinib $(54.2 \%)$ vs. chemotherapy $(0 \%$; $\mathrm{P}<0.001)(47)$. The J-ALEX and ALEX trials $(48,49)$, which compared alectinib with crizotinib in treatment-naïve patients with advanced ALK-positive NSCLC, were phase III studies that revealed the superiority of alectinib over crizotinib. In the J-ALEX trials, the median PFS was not yet reached in the alectinib cohort [95\% CI, 20.3 months-not estimable (NE)] and was 10.2 months in the crizotinib cohort (95\% CI, 8.2-12) in the preplanned interim analysis. ALEX results were similar to those in J-ALEX, with significant improvements in median PFS [alectinib (95\% CI, 17.7 months-NE) vs. crizotinib 11.1 months (95\% CI, 9.1-13.1)]. 

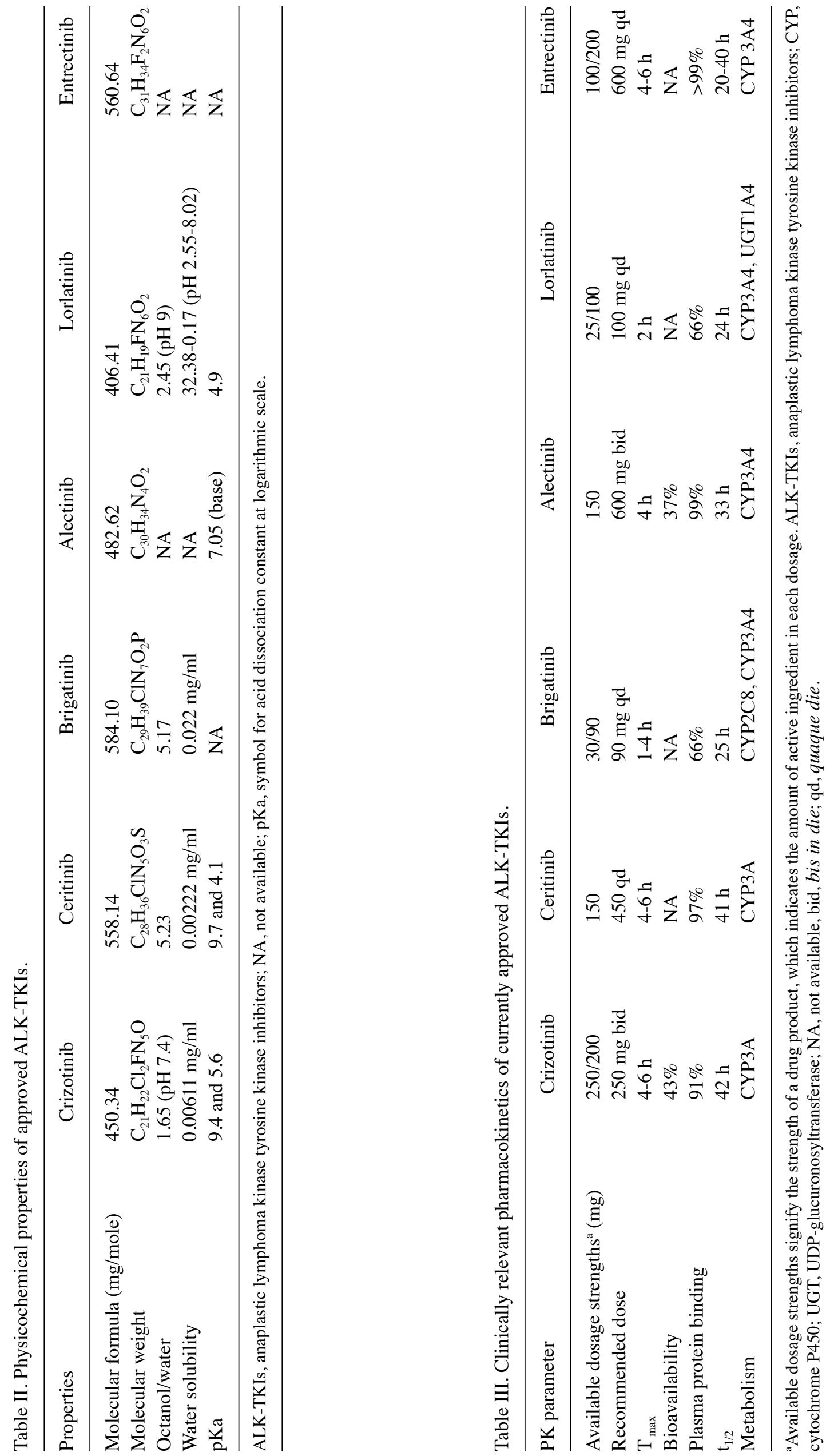


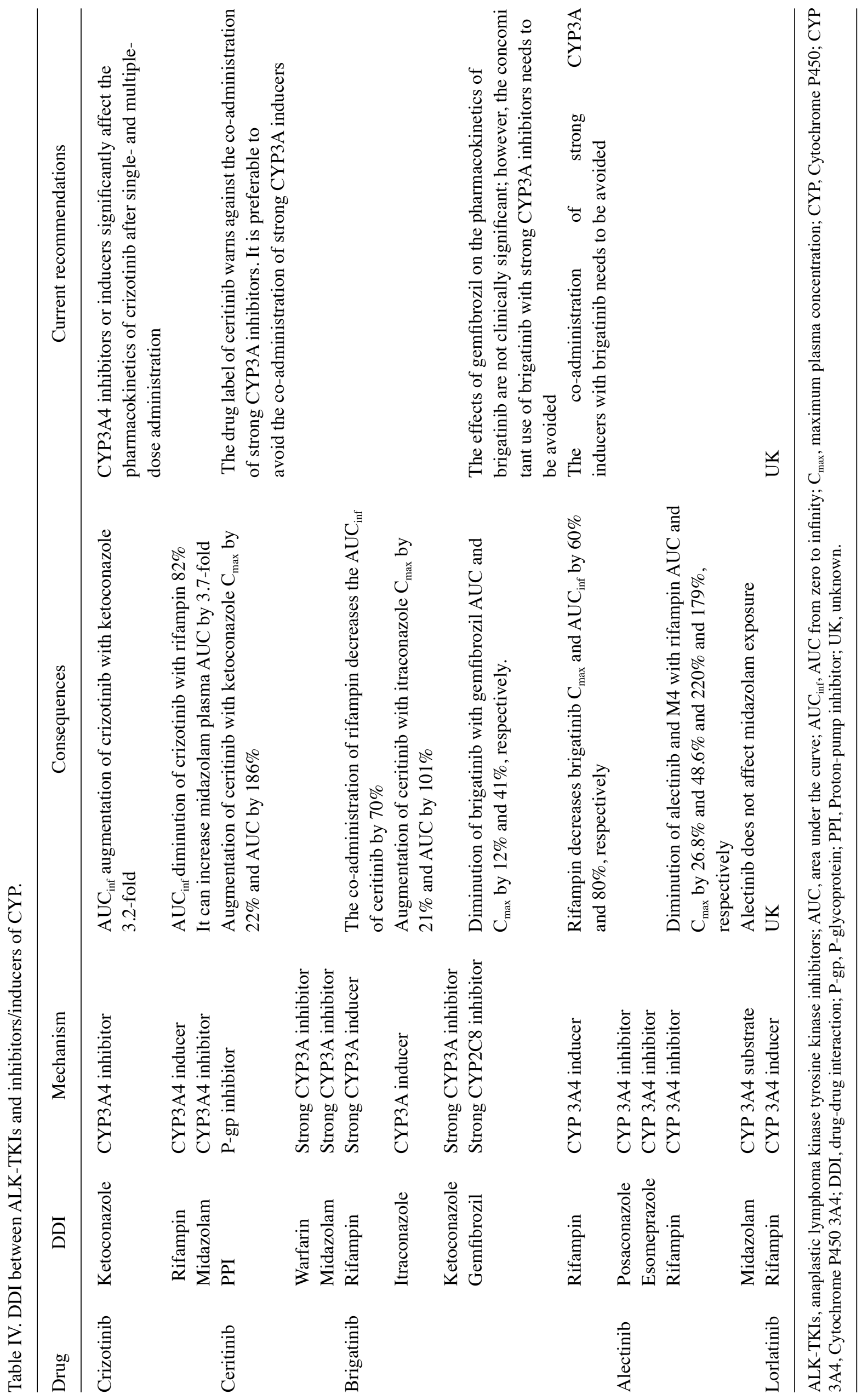




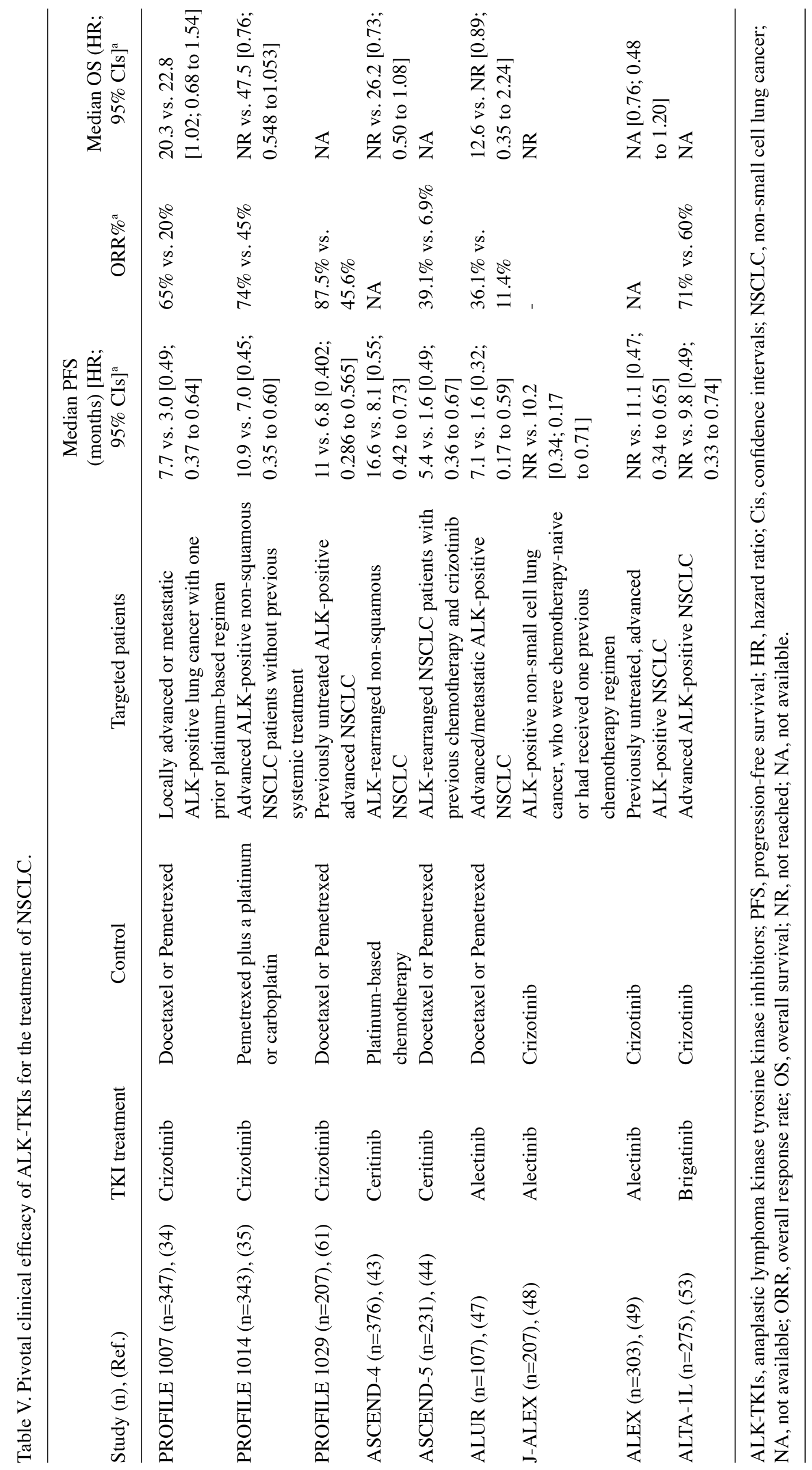




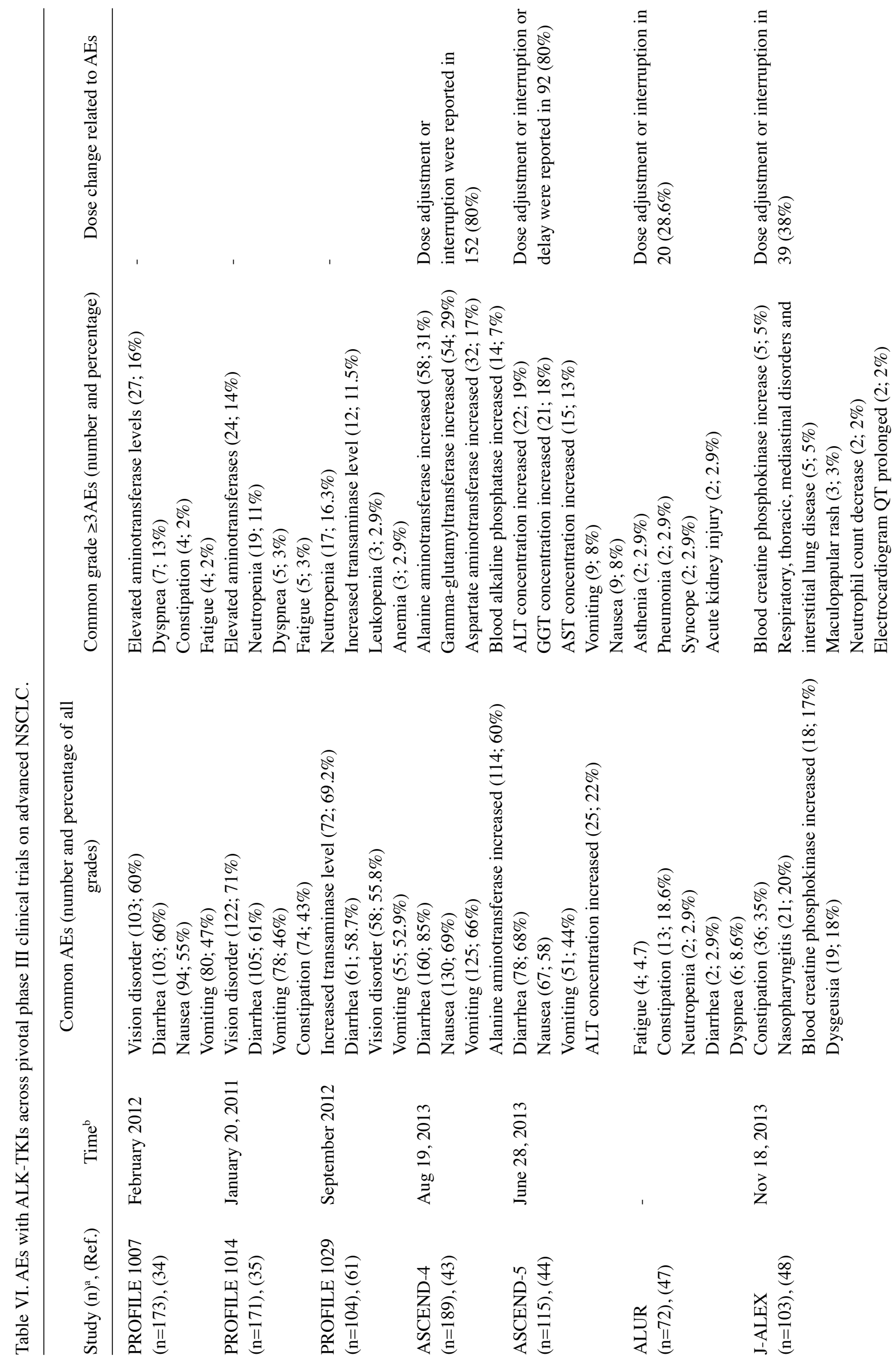


Brigatinib. Brigatinib is a tyrosine kinase inhibitor with broad-spectrum activity against ALK, ROS1, the insulin-like growth factor-1 receptor (IGF-1R), and Fms-like tyrosine kinase 3 (FLT-3), as well as EGFR deletions and point mutations, including L1152R, V1180L, G1202R, R1275Q, T790M, C797S, and L858R $(24,25,50)$. Brigatinib has a 12-fold higher potency than crizotinib for inhibiting ALK. It inhibits crizotinib-, ceritinib-, and alectinib-resistant ALK mutants (24). Brigatinib received approval from the US FDA in 2017 and is indicated for the treatment of patients with ALK-positive metastatic NSCLC who have progressed on or are intolerant to crizotinib. Brigatinib should be taken at a dosage of $90 \mathrm{mg}$ orally once daily for the first 7 days. If patients are tolerant, the dosage should be increased to $180 \mathrm{mg}$ orally once daily. It may be taken with or without food (51). The PK profile of brigatinib is presented in Table III (52). Because brigatinib is primarily metabolized by CYP2C8 and CYP3A (52), this strong inhibitor and inducer, respectively, must affect its exposure. Ariad Pharmaceuticals is investigating the drug-drug interaction between brigatinib and midazolam (52).

Although ceritinib and alectinib can overcome resistance mutations associated with crizotinib, some new resistance mutations still arise. It has been reported that there are seventeen mutations associated with crizotinib, ceritinib and alectinib, including G1202R (22). Brigatinib exhibited activity against this and other mutations. ALTA-1L is a pivotal trial of brigatinib for 1st-line treatment (53). In a randomized, open-label study (53), 275 patients with advanced ALK-positive NSCLC who had been treated with ALK inhibitors were randomly assigned to receive brigatinib or crizotinib. At the follow-up of 12 months, the rate of PFS in the brigatinib arm was higher than that in the crizotinib arm [67\% (95\% CI, 56 to 75$)$ vs. $43 \%$ (95\% CI, 32 to 53)].

Entrectinib. Entrectinib is a selective inhibitor of the tyrosine kinases tropomyosin receptor kinases (Trk) A/B/C, ROS1 and ALK with central nervous system activity $(54,55)$. Entrectinib is 30 times more potent against ROS1 than crizotinib (54). It was approved by the FDA in 2019 as a first-line treatment for adult patients with ROS1-positive metastatic NSCLC and for adult and pediatric patients (12 years of age and older) with solid tumors (55). Adult patients with ROS1-positive metastatic NSCLC and neurotrophic tyrosine receptor kinase (NTRK) gene fusion-positive solid tumors should be administered a dosage of $600 \mathrm{mg}$ orally once daily. For patients 12 years and older with NTRK gene fusion-positive solid tumors, the recommended dosage is based on body surface area (BSA) (55). The PK profile of entrectinib is listed in Table III (56). The clinical activity of entrectinib was assessed in four trials (SATARTRK-1/SATARTRK-2/SATARTRK-NG/ ALKA-372-001) (57), and the efficacy of entrectinib was assessed in patients with ROS1-positive NSCLC [ORR $78 \% ; 65 \%, 89 \%]$, DOR $\geq 9$ months $70 \%$ ). Responses were observed in SATARTRK-1 ALK-rearranged cancer patients $(n=7)$ with an ORR of $57 \%$ and a median PFS of 8.3 months.

\section{Third-generation ALK-TKIs}

Lorlatinib. Lorlatinib is a kinase inhibitor with activity against ALK and ROS1 as well as TYK1, FER, FPS, TRKA/B/C, FAK, FAK2, and ACK, and it can penetrate the blood-brain 


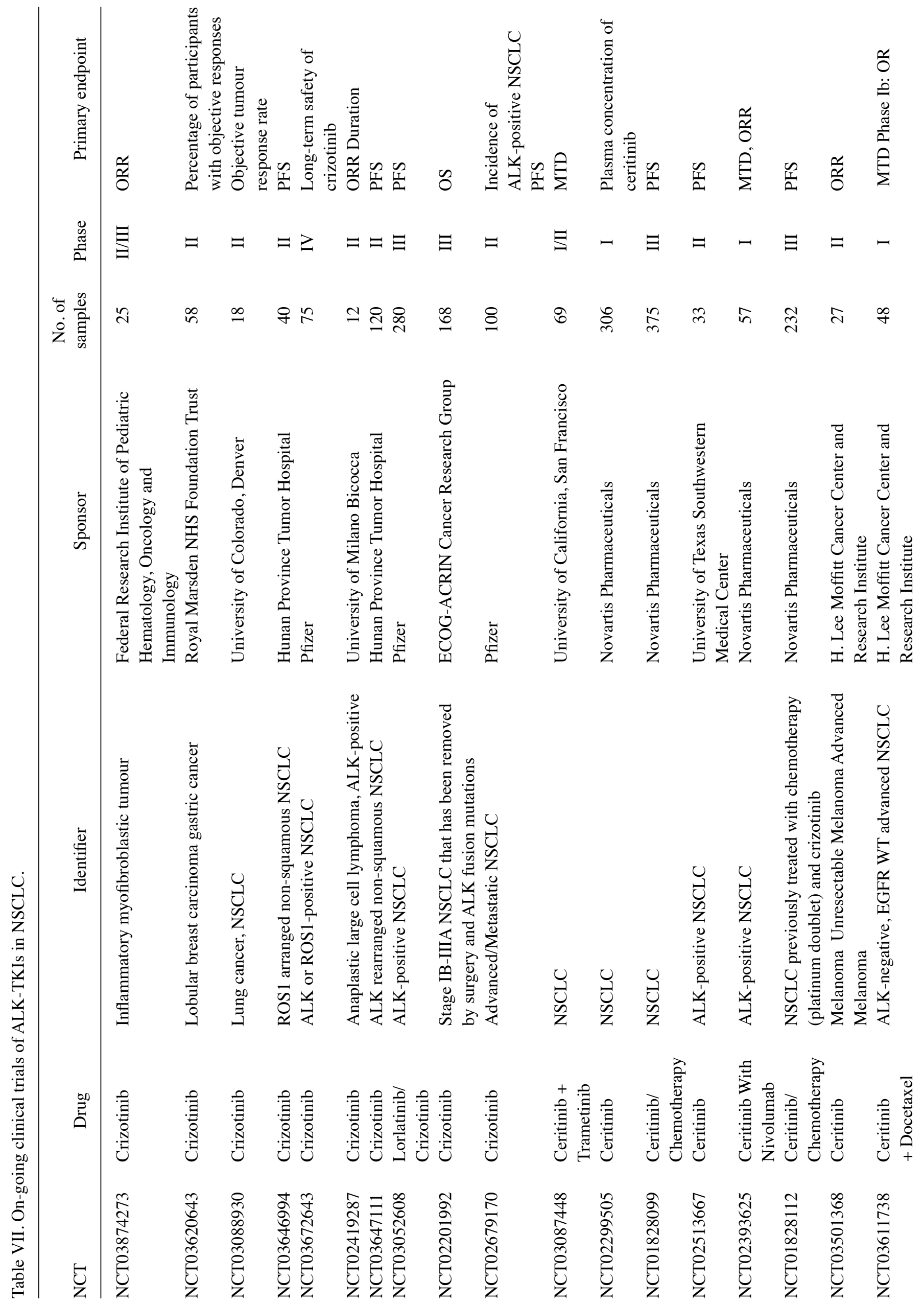




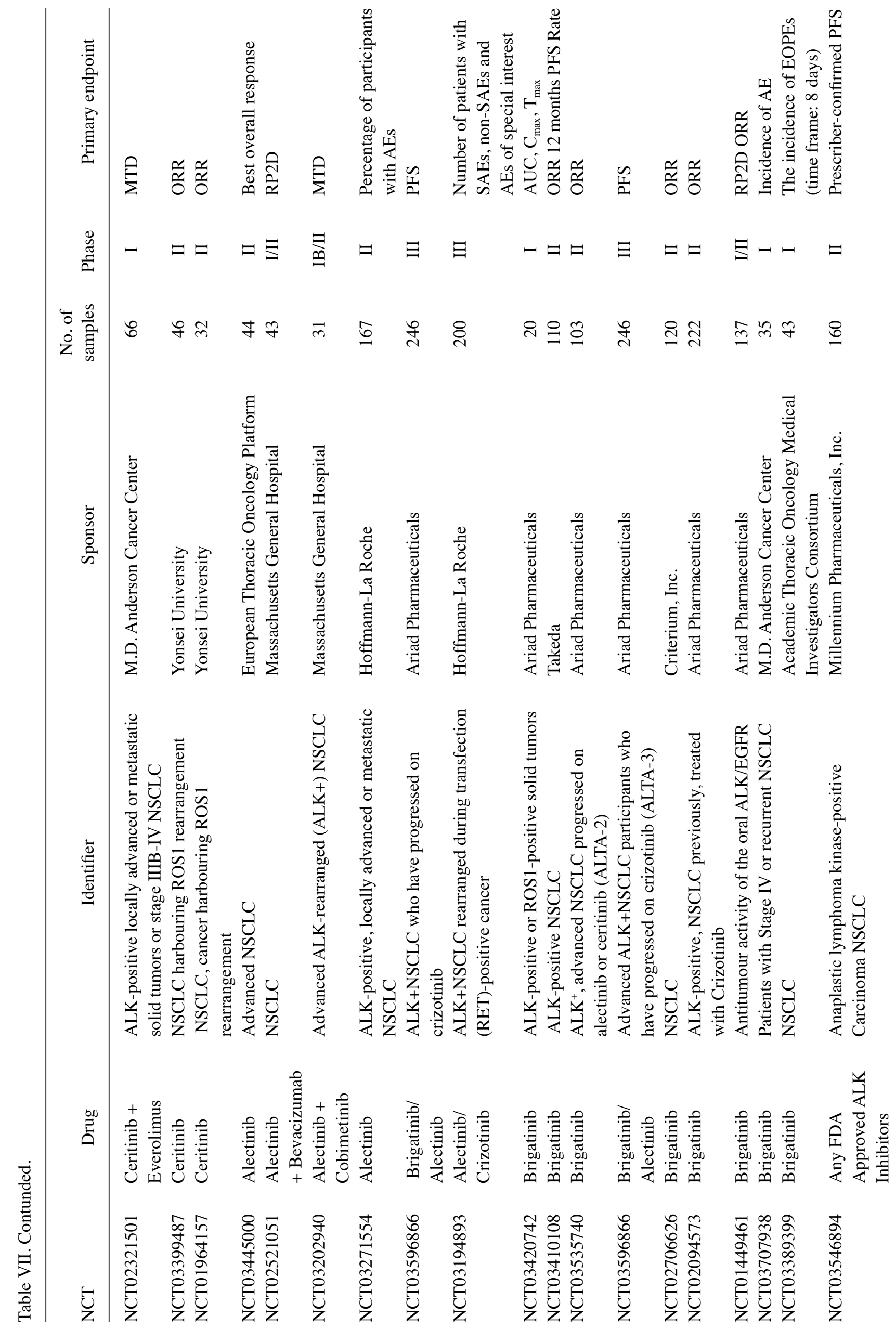




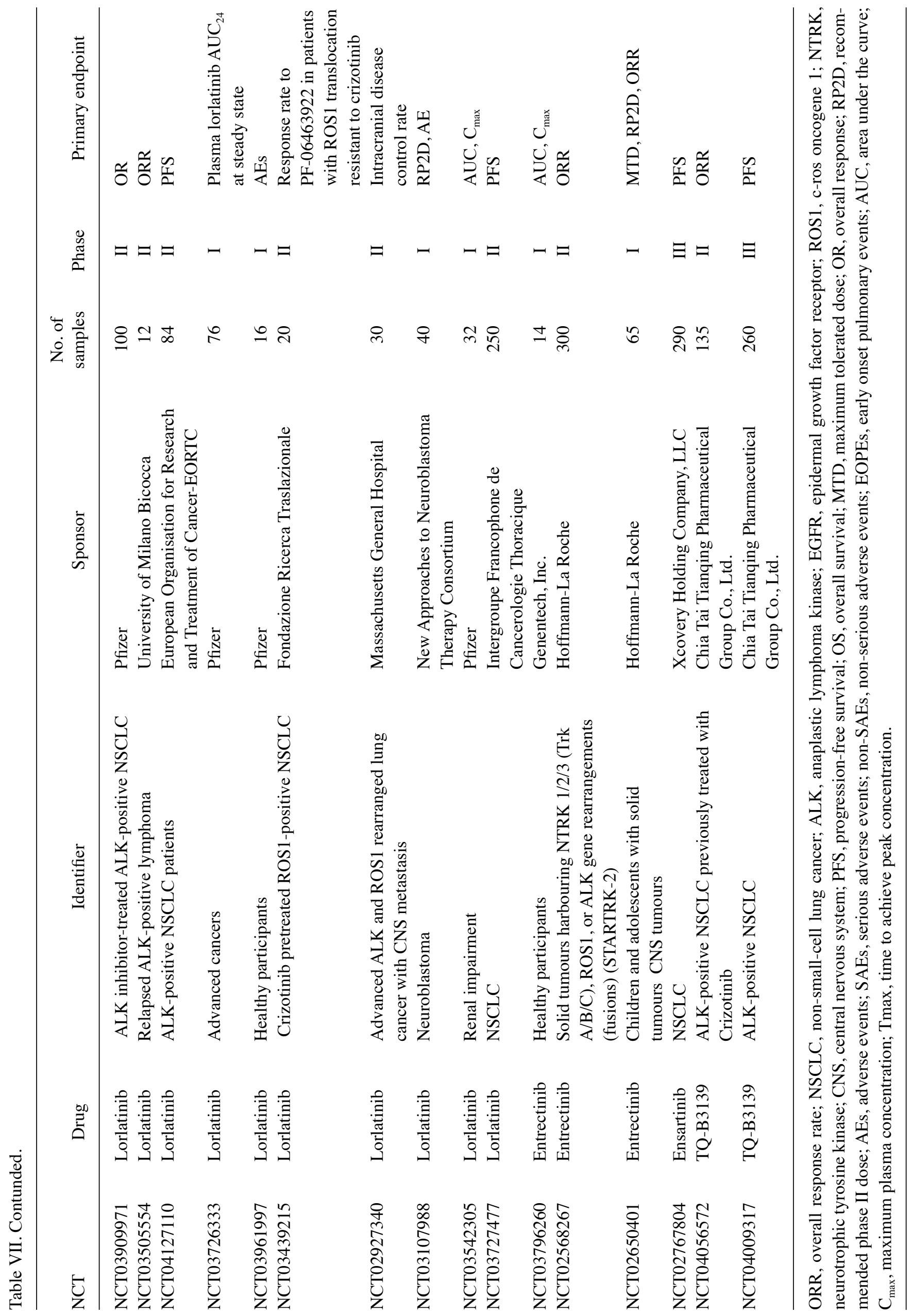


barrier to overcome known ALK resistance mutations (58). In addition, lorlatinib is effective against all known resistant mutants of first- and second-generation ALK inhibitors, such as crizotinib-resistant ALK G1202R and ROS1 G2032R mutants (16). Lorlatinib demonstrates significantly improved (>50-fold) inhibitory potency (59). Lorlatinib received approval from the FDA in 2018 and is indicated for the treatment of patients with ALK-positive metastatic NSCLC whose disease has progressed while taking crizotinib/ceritinib/alectinib as first-line ALK inhibitors for metastatic disease and at least one other ALK inhibitor for metastatic disease. The recommended dosage of lorlatinib is $100 \mathrm{mg}$ orally once daily (58). The PK profile is demonstrated in Table III. Because lorlatinib has high membrane and blood-brain barrier permeability, it is transported by $\mathrm{ABCB} 1$ and $\mathrm{ABCG} 2$ since inhibitors of the transporters $\mathrm{ABCB} 1$ and $\mathrm{ABCG} 2$ influence the concentration of lorlatinib in the brain (60).

Lorlatinib is active against all known acquired resistance mutations associated with earlier TKIs. A phase I dose-escalation study of lorlatinib (NCT03052608) in an array of cancer indications, including ALK-positive NSCLC with two or more previous ALK TKI treatments and ALK-positive NSCLC with brain metastases, demonstrated that lorlatinib was effective for NSCLC patients with acquired resistance to ALK TKIs (33). These impressive results were confirmed by a phase II trial with expansion cohorts in patients with ALK-positive or ROS1-positive advanced NSCLC, revealing that the objective response was $47 \%$ in patients with at least one prior ALK TKI treatment and that the ORR was $90 \%$ in ALK-positive and treatment-naïve patients (33).

\section{Safety evaluation}

Data from certain clinical trials have reported that nausea/vomiting and diarrhea are the most common side effe cts $(34,35,43,44,47-49,53,61)$, which are listed in Table VI. Pneumonitis/interstitial lung disease/pulmonary disease has been described as a relatively rare but serious side effect (62). In ASCEND-1, which aimed to evaluate the safety of ceritinib in a multicenter, single-arm, open-label clinical study of 255 ALK-positive patients, up to $5 \%$ of patients experienced adverse reactions, including (but not limited to) pneumonia, respiratory failure, ILD/pneumonitis, pneumothorax, and gastric hemorrhage. Even fatal events were reported (occurring in $0.2 \%$ of patients) (26).

Hepatotoxicity. Hepatotoxicity is reported relatively frequently in preapproved clinical trials for TKIs as a serious class-related safety issue (63). Concurrently, hepatotoxicity is the leading cause of drug withdrawal in the market. ALK inhibitors are also associated with hepatotoxicity (63). A systematic meta-analysis of clinical trials assessed the incidence and risk of ALK inhibitors (64). Among 1,908 patients from 10 clinical trials, aspartate aminotransferase (AST) elevation accounted for $25.2 \%$, and alanine transaminase (ALT) elevation accounted for $26.0 \%$.

In a clinical trial, hepatobiliary disorders also appeared in patients treated with alectinib, and these disorders included increased levels of AST (3.7\%), ALT (3.7\%) (65) and bilirubin (3.2\%) (64); 1.2-1.5\% of the patients withdrew from treatment due to these adverse reactions (ARs). In the NP28761 study, the levels of alanine aminotransferase and aspartate aminotransferase in patients with alectinib increased by 6 and 5\%, respectively, and two patients withdrew from the study due to hepatotoxicity. In another trial, blood bilirubin levels increased by $15 \%$ (19).

A meta-analysis revealed that the frequencies of grade $\geq 3$ hepatotoxicity induced by ceritinib are greater than those induced by crizotinib or alectinib (66). IGF receptors play an important role, as revealed by the fact that ceritinib inhibits insulin-like growth factor 1 (IGF-1) and insulin receptors and that the IGF receptor is ubiquitous at the cell surface and exists on the surface of cells. Therefore, patients who use alectinib and brigatinib have lower hepatotoxicity than patients who use ceritinib and crizotinib (66). Two analyses reported that the hepatotoxicity induced by alectinib was lower than that induced by crizotinib and ceritinib $(64,67)$.

Although a dose reduction or interruption can occur due to the hepatotoxicity associated with ALK inhibitors, there have been limited studies on the influencing factors. Jung et al (68) reported that the presence of liver disease or HBV and the use of an $\mathrm{H} 2$ antagonist or $\mathrm{H} 2$ antagonist/proton pump inhibitor were the main risk factors for hepatotoxicity induced by crizotinib. A study (67) reporting a histological analysis of patients with acute hepatitis who were treated with alectinib demonstrated that acute hepatitis led to significantly high levels of hepatotoxicity.

Gastrointestinal toxicities. The common toxicities associated with ALK-TKIs are gastrointestinal toxicities, including nausea, vomiting, diarrhea and constipation (65). Although the severity of these toxicities is mild, they are potentially life threatening and can be distressing for patients, affecting their quality of life. Severe diarrhea can result in electrolyte imbalance, renal insufficiency, malnutrition, and extreme dehydration, all of which can lead to cardiovascular compromise and death (69). In a phase I study, a large number of patients $(96 \%$; $14 \%$ severe cases) experienced gastrointestinal (GI) adverse events (AEs) as a result of taking the recommended dose of ceritinib (70). In the XALKORI $(n=171)$ study, up to $61 \%$ of patients who took crizotinib experienced diarrhea, with grade 3-4 diarrhea accounting for $2 \%$ across all clinical trials (26).

GI AEs are one of the most common reasons for dose modification (38\% of patients) (70). Other severe gastrointestinal toxicities, such as vomiting and nausea, occur in patients treated with brigatinib (24\%, grade $3-41.8 \%$; $33 \%$, grade $3-40.9 \%$ ) (71). The incidence and severity of gastrointestinal adverse reactions, including diarrhea, nausea, and vomiting, account for $56 / 45 / 35 \%$ of patients, respectively, and can be reduced with a dose of $450 \mathrm{mg}$ ceritinib taken with food. Nausea (1.8\%) is one of the most frequent adverse reactions that leads to dose reduction in patients taking crizotinib (65). Schaefer and and Baik (70) suggested strategies for potential GI AEs resulting from ceritinib treatment in nine patients, and these recommendations can prevent the need for dose reduction due to GI AEs so that patients can continue taking the prescribed dose ( $750 \mathrm{mg} / \mathrm{d}$ ceritinib dose). Regimens A and B can be implemented as follows: Regimen A consists of ondansetron and diphenoxylate/atropine or loperamide taken 30 min prior to the dose of ceritinib, and Regimen B consists of dicyclomine, which should be taken with the first dose of ceritinib; ondansetron, which should be taken $30 \mathrm{~min}$ prior to 
the dose of ceritinib for the first seven doses; and loperamide, which should be taken as needed with the onset of diarrhea. Although these strategies are not currently recommended or implemented in clinical studies, they provide an option for physicians.

Interstitial lung disease (ILD). ILD has been described as a relatively rare but fatal complication associated with tyrosine kinase inhibitors (72). Lung toxicity has been reported in patients taking ALK-TKIs such as crizotinib, ceritinib, and alectinib, with incidence rates of $1.8,1.1$, and $2.6 \%$, respectively (72). In a retrospective study, only $1.2 \%$ of 1,669 patients treated with crizotinib in clinical trials exhibited crizotinib-related ILD. However, $50 \%$ of those patients succumbed due to ILD (73). Treatment-related deaths (TRDs) were reported in 12 of the 1,365 evaluable patients, resulting in an overall prevalence of $0.9 \%$. The main cause of death was ILD or pneumonitis (66). Severe pulmonary adverse reactions consistent with ILD or pneumonitis occurred with $90 \mathrm{mg}$ brigatinib treatment in $3.7 \%$ of the overall patients and $9.1 \%$ of patients in the $90 / 180 \mathrm{mg}$ group (74).

The risk factors for ILD are not fully understood, but some studies have reported that smoking history, previous or concomitant ILD, and comorbid pleural effusion are associated with ILD, regardless of patient characteristics (73). In other words, ILD represents a potential reason for pulmonary harm. The management strategies for this toxicity are mainly discontinuation and steroid treatment. However, rechallenge with another ALK inhibitor in patients with a previous history of ALK-related ILD and ILD risk factors must be approved via a collegial decision. For example, brigatinib was used in a patient with ALK-rearranged lung adenocarcinoma who developed crizotinib-induced ILD. A cross-link with lung toxicity was not demonstrated in this patient; rather, the patient benefited from that treatment (75).

Cardiac AEs. Cardiac AEs such as Corrected QT (the time between the start of the Q-wave and the end of the T-wave) Interval (QTc) interval prolongation/bradycardia have been reported in patients taking ceritinib/crizotinib/alectinib and brigatinib $(26,71,76,77)$. Symptomatic bradycardia has reportedly emerged in patients treated with alectinib in the NP28761, NP28673 and ALEX studies (78), accounting for 8\%. The heart rates of these patients were less than 50 beats per minute (bpm). Furthermore, patients taking ceritinib experienced QTc interval prolongation and bradycardia. Heart rate decreases and sinus bradycardia were observed in some patients treated with crizotinib, with a reduction of $2.5 \mathrm{bpm}$.

The most effective way to prevent cardiac AEs is to monitor the heart rate and blood pressure of patients regularly during treatment with ALK-TKIs because bradycardia cannot be avoided. Products that cause bradycardia should be avoided when combined with ceritinib/crizotinib/alectinib and brigatinib.

\section{Future directions}

Since the discovery of targeted therapy with ALK, it has been reported that compared to chemotherapeutic agents, ALK inhibitors show improvements in PFS, ORR, and quality of life (2). Furthermore, several new compounds have been synthesized and are under investigation in different phases of clinical trials (Table VII). Based on our own experience, we encourage the early review of potential side effects to minimize any impact of AEs on the quality of life of patients and to help avoid any unnecessary dose reductions or early discontinuations of this effective treatment. With the development of resistance to ALK-TKIs, later-generation ALK-TKIs have been discovered to improve safety profiles (17). However, with disease progression in patients, the switching of ALK-TKIs can be used to identify the mutations and rearrangements of ALK $(11,17)$. In other words, it is helpful to understand the resistance mechanisms. While the current technology used for liquid biopsy to detect late mutations in ALK is well justified, greater efforts are also required to minimize the clinical risks that adversely impact morbidity and quality of life. Finally, chemotherapy is also a valid choice for patients with ALK-positive metastatic NSCLC.

\section{Acknowledgements}

Not applicable.

Funding

No funding was received.

\section{Availability of data and materials}

Not applicable.

\section{Authors' contributions}

WL wrote the paper. WW reviewed and edited the manuscript. Both authors read and approved the manuscript.

\section{Ethics approval and consent to participate}

Not applicable.

\section{Patient consent for publication}

Not applicable.

\section{Competing interests}

The authors declare that they have no competing interests.

\section{References}

1. Duffy MJ and O'Byrne K: Tissue and blood biomarkers in lung cancer: A review. Adv Clin Chem 86: 1-21, 2018.

2. Khan M, Lin J, Liao G, Tian Y, Liang Y, Li R, Liu M and Yuan Y: ALK inhibitors in the treatment of ALK positive NSCLC. Front Oncol 8: 557, 2019.

3. Melosky B, Cheema P, Agulnik J, Albadine R, Bebb DG, Blais N, Burkes R, Butts C, Card PB, Chan AMY, et al: Canadian perspectives: Update on inhibition of ALK-positive tumours in advanced non-small-cell lung cancer. Curr Oncol 25: 317-328, 2018.

4. Soda M, Choi YL,Enomoto M,Takada S, Yamashita Y,Ishikawa S, Fujiwara S, Watanabe H, Kurashina K, Hatanaka $\mathrm{H}$, et al: Identification of the transforming EML4-ALK fusion gene in non-small-cell lung cancer. Nature 448: 561-566, 2007.

5. Chan BA and Hughes BG: Targeted therapy for non-small cell lung cancer: Current standards and the promise of the future. Transl Lung Cancer Res 4: 36-54, 2015. 
6. D'Arcangelo M,Wynes MW and Hirsch FR: The role of anaplastic lymphoma kinase inhibitors in the treatment of advanced nonsmall cell lung cancer. Curr Opin Oncol 25: 121-129, 2013.

7. Huang H: Anaplastic lymphoma kinase (ALK) receptor tyrosine kinase: A catalytic receptor with many faces. Int J Mol Sci 19: 3448, 2018.

8. Golding B, Luu A, Jones R and Viloria-Petit AM: The function and therapeutic targeting of anaplastic lymphoma kinase (ALK) in non-small cell lung cancer (NSCLC). Mol Cancer 17: 52,2018

9. Roskoski R Jr: Anaplastic lymphoma kinase (ALK) inhibitors in the treatment of ALK-driven lung cancers. Pharmacol Res 117: 343-356, 2017.

10. Zhang Z, Guo H, Lu Y, Hao W and Han L: Anaplastic lymphoma kinase inhibitors in non-small cell lung cancer patients with brain metastases: A meta-analysis. J Thorac Dis 11: 1397-1409, 2019.

11. Sgambato A, Casaluce F, Maione P and Gridelli C: Targeted therapies in non-small cell lung cancer: A focus on ALK/ROS1 tyrosine kinase inhibitors. Expert Rev Anticancer Ther 18: 71-80, 2018.

12. Cui S, Zhao Y, Gu A, Ge X, Song Y, Zhang W, Lou Y, Dong L, Han B and Jiang L: Efficacy and tolerability of crizotinib in the treatment of ALK-positive, advanced non-small cell lung cancer in Chinese patients. Med Oncol 32: 626, 2015.

13. Califano R, Greystoke A, Lal R, Thompson J and Popat S: Management of ceritinib therapy and adverse events in patients with ALK-rearranged non-small cell lung cancer. Lung Cancer 111: 51-58, 2017.

14. Zhu V and Ou SH: Safety of alectinib for the treatment of metastatic ALK-rearranged non-small cell lung cancer. Expert Opin Drug Saf 16: 509-514, 2017

15. Sabari JK, Santini FC, Schram AM, Bergagnini I, Chen R, Mrad C, Lai WV, Arbour KC and Drilon A: The activity, safety, and evolving role of brigatinib in patients with ALK-rearranged non-small cell lung cancers. Onco Targets Ther 10: 1983-1992, 2017.

16. Bauer TM, Felip E, Solomon BJ, Thurm H, Peltz G, Chioda MD and Shaw AT: Clinical management of adverse events associated with lorlatinib. Oncologist 24: 1103-1110, 2019

17. Spagnuolo A, Maione $\mathrm{P}$ and Gridelli C: Evolution in the treatment landscape of non-small cell lung cancer with ALK gene alterations: From the first- to third-generation of ALK inhibitors. Expert Opin Emerg Drugs 23: 231-241, 2018.

18. Gadgeel SM: The use of alectinib in the first-line treatment of anaplastic lymphoma kinase-positive non-small-cell lung cancer. Future Oncol 14: 1875-1882, 2018.

19. Vavala $T$ and Novello S: Alectinib in the treatment of ALK-positive non-small cell lung cancer: An update on its properties, efficacy, safety and place in therapy. Ther Adv Med Oncol 10: 1758835918789364, 2018.

20. Paik J and Dhillon S: Alectinib: A review in advanced, ALK-positive NSCLC. Drugs 78: 1247-1257, 2018

21. Cortinovis D, Canova S, Abbate MI, Colonese F, Cogliati V and Bidoli P: Challenges in ALK inhibition of ALK-positive non-small-cell lung cancer: From ALK positivity detection to treatment strategies after relapse. Future Oncol 14: 2303-2317, 2018.

22. Peters S and Zimmermann S: Management of resistance to first-line anaplastic lymphoma kinase tyrosine kinase inhibitor therapy. Curr Treat Options Oncol 19: 37, 2018.

23. Dagogo-Jack I and Shaw AT: Crizotinib resistance: Implications for therapeutic strategies. Ann Oncol 27 (Suppl 3): iii42-iii50, 2016.

24. Ali R, Arshad J, Palacio S and Mudad R: Brigatinib for ALK-positive metastatic non-small-cell lung cancer: Design, development and place in therapy. Drug Des Devel Ther 13: 569-580, 2019.

25. Bedi S, Khan SA, AbuKhader MM, Alam P, Siddiqui NA and Husain A: A comprehensive review on Brigatinib-A wonder drug for targeted cancer therapy in non-small cell lung cancer. Saudi Pharm J 26: 755-763, 2018.

26. Pfizer Inc.: XALKORI 2011. https://www.accessdata.fda gov/drugsatfda_docs/label/2019/202570s028lbl.pdf. Accessed January $10,2019$.

27. Xu H, O'Gorman M, Boutros T, Brega N, Kantaridis C, Tan W and Bello A: Evaluation of crizotinib absolute bioavailability, the bioequivalence of three oral formulations, and the effect of food on crizotinib pharmacokinetics in healthy subjects. J Clin Pharmacol 55: 104-113, 2015.
28. Hamilton G, Rath B and Burghuber O: Pharmacokinetics of crizotinib in NSCLC patients. Expert Opin Drug Metab Toxicol 11: 835-842, 2015

29. Fujiwara Y, Hamada A, Mizugaki H, Aikawa H, Hata T, Horinouchi $\mathrm{H}$, Kanda $\mathrm{S}$, Goto $\mathrm{Y}$, Itahashi $\mathrm{K}$, Nokihara $\mathrm{H}$, et al: Pharmacokinetic profiles of significant adverse events with crizotinib in Japanese patients with ABCB1 polymorphism. Cancer Sci 107: 1117-1123, 2016.

30. El-Khoueiry AB, Sarantopoulos J, O'Bryant CL, Ciombor KK, Xu H, O'Gorman M, Chakrabarti J, Usari T and El-Rayes BF: Evaluation of hepatic impairment on pharmacokinetics and safety of crizotinib in patients with advanced cancer. Cancer Chemother Pharmacol 81: 659-670, 2018.

31. Tan W, Yamazaki S, Johnson TR, Wang R, O'Gorman MT, Kirkovsky L, Boutros T, Brega NM and Bello A: Effects of renal function on crizotinib pharmacokinetics: Dose recommendations for patients with ALK-positive non-small cell lung cancer. Clin Drug Investig 37: 363-373, 2017.

32. Hirota T, Muraki S and Ieiri I: Clinical pharmacokinetics of anaplastic lymphoma kinase inhibitors in non-small-cell lung cancer. Clin Pharmacokinet 58: 403-420, 2019.

33. Pirker R and Filipits M: From crizotinib to lorlatinib: Continuous improvement in precision treatment of ALK-positive non-small cell lung cancer. ESMO Open 4: e000548, 2019.

34. Shaw AT, Kim DW, Nakagawa K, Seto T, Crinó L, Ahn MJ, De Pas T, Besse B, Solomon BJ, Blackhall F, et al: Crizotinib versus chemotherapy in advanced ALK-positive lung cancer. N Engl J Med 368: 2385-2394, 2013.

35. Solomon BJ, Mok T, Kim DW, Wu YL, Nakagawa K, Mekhail T, Felip E, Cappuzzo F, Paolini J, Usari T, et al: First-line crizotinib versus chemotherapy in ALK-positive lung cancer. N Engl J Med 371: 2167-2177, 2014

36. Nishio M, Kim DW, Wu YL, Nakagawa K, Solomon BJ, Shaw AT, Hashigaki S, Ohki E, Usari T, Paolini J, et al: Crizotinib versus chemotherapy in asian patients with ALK-positive advanced non-small cell lung cancer. Cancer Res Treat 50: 691-700, 2018.

37. Deeks ED: Ceritinib: A review in ALK-positive advanced NSCLC. Target Oncol 11: 693-700, 2016.

38. Tomasini P, Egea J, Souquet-Bressand M, Greillier L and Barlesi F: Alectinib in the treatment of ALK-positive metastatic non-small cell lung cancer: Clinical trial evidence and experience with a focus on brain metastases. Ther Adv Respir Dis 13: 1753466619831906, 2019.

39. Claxton L, O'Connor J, Woolacott N, Wright K and Hodgson R: Ceritinib for untreated anaplastic lymphoma kinase-positive advanced non-small-cell lung cancer: An evidence review group evaluation of a NICE single technology appraisal. Pharmacoeconomics 37: 645-654, 2019.

40. Friboulet L, Li N, Katayama R, Lee CC, Gainor JF, Crystal AS, Michellys PY, Awad MM, Yanagitani N, Kim S, et al: The ALK inhibitor ceritinib overcomes crizotinib resistance in non-small cell lung cancer. Cancer Discov 4: 662-673, 2014.

41. Shaw AT, Kim DW, Mehra R, Tan DS, Felip E, Chow LQ, Camidge DR, Vansteenkiste J, Sharma S, De Pas T, et al: Ceritinib in ALK-rearranged non-small-cell lung cancer. N Engl J Med 370: 1189-1197, 2014.

42. Gainor JF and Shaw AT: Fast, food and ceritinib in ALK-positive NSCLC. J Thorac Oncol 12: 1341-1343, 2017.

43. Soria JC, Tan DSW, Chiari R, Wu YL, Paz-Ares L, Wolf J, Geater SL, Orlov S, Cortinovis D, Yu CJ, et al: First-line ceritinib versus platinum-based chemotherapy in advanced ALK-rearranged non-small-cell lung cancer (ASCEND-4): A randomised, open-label, phase 3 study. Lancet 389: 917-929, 2017.

44. Shaw AT, Kim TM, Crinò L, Gridelli C, Kiura K, Liu G, Novello S, Bearz A, Gautschi O, Mok T, et al: Ceritinib versus chemotherapy in patients with ALK-rearranged non-small-cell lung cancer previously given chemotherapy and crizotinib (ASCEND-5): A randomised, controlled, open-label, phase 3 trial. Lancet Oncol 18: 874-886, 2017.

45. Beardslee $\mathrm{T}$ and Lawson $\mathrm{J}$ : Alectinib and brigatinib: New second-generation ALK inhibitors for the treatment of non-small cell lung cancer. J Adv Pract Oncol 9: 94-101, 2018.

46. Parrott NJ, Yu LJ, Takano R, Nakamura M and Morcos PN: Physiologically based absorption modeling to explore the impact of food and gastric $\mathrm{pH}$ changes on the pharmacokinetics of alectinib. AAPS J 18: 1464-1474, 2016.

47. Novello S, Mazieres J, Oh IJ, de Castro J, Migliorino MR, Helland Å, Dziadziuszko R, Griesinger F, Kotb A, Zeaiter A, et al: Alectinib versus chemotherapy in crizotinib-pretreated anaplastic lymphoma kinase (ALK)-positive non-small-cell lung cancer: Results from the phase III ALUR study. Ann Oncol 29: 1409-1416, 2018. 
48. Hida T, Nokihara H, Kondo M, Kim YH, Azuma K, Seto T, Takiguchi Y, Nishio M, Yoshioka H, Imamura F, et al: Alectinib versus crizotinib in patients with ALK-positive non-small-cell lung cancer (J-ALEX): An open-label, randomised phase 3 trial. Lancet 390: 29-39, 2017.

49. Peters S, Camidge DR, Shaw AT, Gadgeel S, Ahn JS, Kim DW, Ou SI, Pérol M, Dziadziuszko R, Rosell R, et al: Alectinib versus crizotinib in untreated ALK-positive non-small-cell lung cancer. N Engl J Med 377: 829-838, 2017.

50. Umbela S, Ghacha S, Matuknauth R, Gause S, Joshee S and Deshmukh RR: Brigatinib: New-generation ALK inhibitor for nonsmall cell lung cancer. Curr Probl Cancer 43: 100477, 2019.

51. Markham A: Brigatinib: First global approval. Drugs 77: 1131-1135, 2017.

52. Tugnait M, Gupta N, Hanley MJ, Sonnichsen D, Kerstein D, Dorer DJ, Venkatakrishnan K and Narasimhan N: Effects of strong CYP2C8 or CYP3A inhibition and CYP3A induction on the pharmacokinetics of brigatinib, an oral anaplastic lymphoma kinase inhibitor, in healthy volunteers. Clin Pharmacol Drug Dev 9: 214-223, 2020

53. Camidge DR, Kim HR, Ahn MJ, Yang JC, Han JY, Lee JS, Hochmair MJ, Li JY, Chang GC, Lee KH, et al: Brigatinib versus crizotinib in ALK-positive non-small-cell lung cancer. N Engl J Med 379: 2027-2039, 2018.

54. Al-Salama ZT and Keam SJ: Entrectinib: First global approval. Drugs 79: 1477-1483, 2019.

55. Genentech Inc: ROZLYTREK 2019. https://www.accessdata.fda gov/drugsatfda_docs/label/2019/212726s000lbl.pdf. Accessed January 10, 2019.

56. Wang Q, Fang P, Zheng L and Ye L: Quantification and pharmacokinetic study of entrectinib in rat plasma using ultra-performance liquid chromatography tandem mass spectrometry. Biomed Chromatogr 33: e4467, 2019.

57. Liu D, Offin M, Harnicar S, Li BT and Drilon A: Entrectinib: An orally available, selective tyrosine kinase inhibitor for the treatment of NTRK, ROS1, and ALK fusion-positive solid tumors. Ther Clin Risk Manag 14: 1247-1252, 2018.

58. Pfizer Inc: Lorbrena 2018. https://www.accessdata.fda.gov/drugsatfda_docs/label/2018/210868s000lbl.pdf. Accessed January 10, 2019.

59. Akamine T, Toyokawa G, Tagawa T and Seto T: Spotlight on lorlatinib and its potential in the treatment of NSCLC: The evidence to date. Onco Targets Ther 11: 5093-5101, 2018.

60. Li W, Sparidans RW, Wang Y, Lebre MC, Wagenaar E, Beijnen JH and Schinkel AH: P-glycoprotein (MDR1/ABCB1) restricts brain accumulation and cytochrome P450-3A (CYP3A) limits oral availability of the novel ALK/ROS1 inhibitor lorlatinib. Int J Cancer 143: 2029-2038, 2018.

61. Wu YL, Lu S, Lu Y, Zhou J, Shi YK, Sriuranpong V, Ho JCM, Ong CK, Tsai CM, Chung CH, et al: Results of PROFILE 1029, a phase III comparison of first-line crizotinib versus chemotherapy in east asian patients with ALK-positive advanced non-small cell lung cancer. J Thorac Oncol 13: 1539-1548, 2018.

62. Yoneda KY, Scranton JR, Cadogan MA, Tassell V, Nadanaciva S, Wilner KD and Stollenwerk NS: Interstitial lung disease associated with crizotinib in patients with advanced non-small cell lung cancer: Independent review of four PROFILE trials. Clin Lung Cancer 18: 472-479, 2017.

63. Shah RR, Morganroth J and Shah DR: Hepatotoxicity of tyrosine kinase inhibitors: Clinical and regulatory perspectives. Drug Saf 36: 491-503, 2013

64. Liu B, Yuan M, Sun Y, Cheng Z, Zhang Z, Hou S, Wang X and Liu J: Incidence and risk of hepatic toxicities associated with anaplastic lymphoma kinase inhibitors in the treatment of non-small-cell lung cancer: A systematic review and meta-analysis. Oncotarget 9: 9480-9488, 2017.
65. Costa RB, Costa RLB, Talamantes SM, Kaplan JB, Bhave MA, Rademaker A, Miller C, Carneiro BA, Mahalingam D and Chae YK: Systematic review and meta-analysis of selected toxicities of approved ALK inhibitors in metastatic non-small cell lung cancer. Oncotarget 9: 22137-22146, 2018.

66. Zhu Q, Hu H, Weng DS, Zhang XF, Chen CL, Zhou ZQ, Tang Y and Xia JC: Pooled safety analyses of ALK-TKI inhibitor in ALK-positive NSCLC. BMC Cancer 17: 412, 2017.

67. Zhu VW, Lu Y and Ou SI: Severe acute hepatitis in a patient receiving alectinib for ALK-positive non-small-cell lung cancer: Histologic analysis. Clin Lung Cancer 20: e77-e80, 2019.

68. Jung D, Han JM, Yee J, Kim JY and Gwak HS: Factors affecting crizotinib-induced hepatotoxicity in non-small cell lung cancer patients. Med Oncol 35: 154, 2018.

69. Van Sebille YZ, Gibson RJ, Wardill HR and Bowen JM: ErbB small molecule tyrosine kinase inhibitor (TKI) induced diarrhoea: Chloride secretion as a mechanistic hypothesis. Cancer Treat Rev 41: 646-652, 2015.

70. Schaefer ES and Baik C: Proactive management strategies for potential gastrointestinal adverse reactions with ceritinib in patients with advanced ALK-positive non-small-cell lung cancer. Cancer Manag Res 8: 33-38, 2016.

71. Ariad: ALUNBRIG. 2017. https://www.accessdata.fda gov/drugsatfda_docs/label/2017/208772lbl.pdf. Accessed January 10, 2019.

72. Pellegrino B, Facchinetti F, Bordi P, Silva M, Gnetti L and Tiseo M: Lung toxicity in non-small-cell lung cancer patients exposed to ALK inhibitors: Report of a peculiar case and systematic review of the literature. Clin Lung Cancer 19: e151-e161, 2018.

73. Gemma A, Kusumoto M, Kurihara Y, Masuda N, Banno S, Endo Y, Houzawa H, Ueno N, Ohki E and Yoshimura A: Interstitial lung disease onset and its risk factors in Japanese patients with ALK-positive NSCLC after treatment with crizotinib. J Thorac Oncol 14: 672-682, 2019.

74. Gettinger SN, Bazhenova LA, Langer CJ, Salgia R, Gold KA, Rosell R, Shaw AT, Weiss GJ, Tugnait M, Narasimhan NI, et al: Activity and safety of brigatinib in ALK-rearranged non-small-cell lung cancer and other malignancies: A single-arm, open-label, phase 1/2 trial. Lancet Oncol 17: 1683-1696, 2016.

75. Domenech M, Jove M, Aso S, Marin M and Nadal E: Successful treatment with brigatinib in a patient with ALK-rearranged lung adenocarcinoma who developed crizotinib-induced interstitial lung disease. Lung Cancer 119: 99-102, 2018.

76. Novartis Inc: Zykadia. 2014. Available from: https://www. pharma.us.novartis.com/product/pi/pdf/zykadia.pdf. Accessed January 10, 2019.

77. Hoffmann-La Roche: ALECENSA. 2015. https://www. accessdata.fda.gov/drugsatfda_docs/label/2018/208434s004lbl. pdf. Accessed January 10,2019.

78. Morcos PN, Bogman K, Hubeaux S, Sturm-Pellanda C, Ruf T, Bordogna W, Golding S, Zeaiter A, Abt M and Balas B: Effect of alectinib on cardiac electrophysiology: Results from intensive electrocardiogram monitoring from the pivotal phase II NP28761 and NP28673 studies. Cancer Chemother Pharmacol 79: 559-568, 2017.

This work is licensed under a Creative Commons Attribution-NonCommercial-NoDerivatives 4.0 International (CC BY-NC-ND 4.0) License. 